\title{
REVIEW
}

\section{Open questions for Alzheimer's disease immunotherapy}

Todd E Golde

\begin{abstract}
Perhaps more definitively than any other class of novel Alzheimer's disease (AD) therapy, pre-clinical studies in mouse models of amyloid $\beta(A \beta)$ deposition have established the disease-modifying potential of anti-A $\beta$ immunotherapy. Despite disappointing results to date from anti-A $\beta$ immunotherapy therapeutic trials, there is continued hope that such immunotherapies, especially if used in the preclinical stages, could prove to be the first disease-modifying therapies available for AD. The general optimism that A $\beta$-targeting and emerging tau-targeting immunotherapies may prove to be disease modifying is tempered by many unanswered questions regarding these therapeutic approaches, including but not limited to i) lack of precise understanding of mechanisms of action, ii) the factors that regulate antibody exposure in the brain, iii) the optimal target epitope, and iv) the mechanisms underlying side effects. In this review I discuss how answering these and other questions could increase the likelihood of therapeutic success. As passive immunotherapies are also likely to be extremely expensive, I also raise questions relating to cost-benefit of biologic-based therapies for AD that could limit future impact of these therapies by limiting access due to economic constraints.
\end{abstract}

\section{Introduction}

Over the past several years, data from human trials testing the efficacy of anti-amyloid $\beta$ (anti-A $\beta$ ) immunotherapies and intravenous immunoglobulin in symptomatic Alzheimer's disease (AD) patients have been disappointing, although this is perhaps not unexpected. Yet despite these clinical setbacks, development and clinical testing of immunotherapies for $\mathrm{AD}$ remain the most active areas of both clinical and pre-clinical development [1]. For over a decade, the main target of immunotherapies has been $A \beta$, but in the past few years anti-tau immunotherapies have emerged and are rapidly advancing to the clinic. Despite the huge investments, both in therapeutic development and clinical testing, there remain many fundamental gaps in our knowledge regarding how immunotherapies for $\mathrm{AD}$ work and how to optimize them [2]. In this review, I address some of these gaps in our knowledge and discuss how filling them in will likely result in therapeutics more likely to have significant clinical efficacy.

\footnotetext{
Correspondence: tgolde@ufl.edu
}

Department of Neuroscience, Center for Translational Research in Neurodegenerative Disease, and McKnight Brain Institute, College of Medicine, University of Florida, Gainesville, FL 32610, USA

\section{Is brain exposure the key?}

The issue of how a small amount of anti-A $\beta$ monoclonal antibody $(\mathrm{mAb})$ present in the brain following peripheral dosing can have a therapeutic effect on plaque pathology has posed a dilemma for the field. It is well established that steady state central nervous system (CNS) levels of a peripherally administered anti- $\mathrm{A} \beta \mathrm{mAb}$ are approximately $0.1 \%$ of the levels found in the plasma [3-5]. Although it remains remotely plausible that anti-A $\beta$ therapy promotes efflux of $A \beta$ or an $A \beta$ aggregate from the brain to the plasma via a peripheral sink [6], a growing body of evidence suggests that $\mathrm{mAb}$ exposure in the brain is critical for efficacy [2]. If this proves to be the case, then increasing total $\mathrm{mAb} C \mathrm{CNS}$ exposure can have a huge positive impact on efficacy. Indeed, given a set of anti-A $\beta$ mAbs with similar pharmacokinetic properties, one would predict that those that can be dosed at higher levels would be more efficacious. Alternatively, efforts to increase brain uptake (for example, by hijacking transferrin or insulin receptor-mediated transcytosis machinery $[7,8]$ ) might also be worth the extensive antibody engineering required to achieve modest, but nevertheless significant, increases in brain exposure [5]. In support of this concept, two preclinical studies, one testing mAb infusion via mini pumps into the ventricles and another testing the effects of direct 
transgenic expression in the brain of an anti- $\mathrm{A} \beta \mathrm{mAb}$, both demonstrate enhanced efficacy relative to peripheral $\mathrm{mAb}$ administration $[9,10]$. Although some in the field remain skeptical about a central mechanism of action of anti-A $\beta$ antibodies in the brain, there are numerous examples of peripherally produced natural antibodies that cause neurological syndromes by targeting a CNS protein $[11,12]$. Thus, for remaining skeptics I would simply state that if a peripherally produced antibody can cause CNS disease, then a peripherally injected antibody that targets a pathologic target should also be capable of having a therapeutic effect.

A more general review of the literature reveals that there is a paucity of data regarding antibody exposure in the CNS. Based on findings that centrally administered antibodies are rapidly exported to the periphery, it nevertheless appears likely that there is cycling of the mAb between the CNS and plasma compartments [3-5]. Thus, the $0.1 \%$ of antibody should not be viewed as in a static steady state, but rather a dynamic equilibrium in which the mAb rapidly enters the brain and subsequently is rapidly exported from the brain. As shown in Figure 1, if the cycling time is rapid (for example, 1 hour) one can estimate that CNS exposures of a human therapeutic dose of anti-A $\beta$ could influence $A \beta$ through stoichiometric binding. Given the limited data available, it would seem that a renewed effort to understand $\mathrm{mAb}$ efflux from the brain is warranted. If mAb cycling times are fast and the influx and efflux mechanisms are distinct, it may be possible to increase CNS mAb exposure by identifying and then manipulating these mechanisms. Alternatively, perhaps we should collectively consider direct infusion of the mAb into the brain [9]. Indeed, given the costs of mAb production and the amounts required in current trials (typically 2 to $3 \mathrm{~g}$ per patient), direct infusion might require dramatically less $\mathrm{mAb}$ to achieve equivalent efficacy. Although it would be more invasive, direct infusion might be more cost-effective. Furthermore, direct infusion of the mAb might also be used as proof of concept studies in small human trials to establish efficacy with no uncertainty regarding sufficient brain exposure. Two caveats with respect to possible clinical trials of direct infusion studies would be the unknowns regarding how the antibodies distribute in the brain following infusion and how site of infusion might influence that distribution.

The neonatal $\mathrm{Fc}$ receptor $(\mathrm{FcRn})$ is a major mediator of immunoglobulin (Ig)G transcytosis and recycling of IgG that is initially taken up by cells through fluid phase endocytosis (reviewed in [13]). Although FcRn has been reported to mediate efflux of IgG from the CNS to the blood [14] and also play a role in IgG assisted clearance of $A \beta$ [15], other data suggest that FcRn and other FcR-mediated mechanisms of efflux may be more complicated [16]. Indeed, studies in FcRn-deficient mice have demonstrated that the brain levels of IgG are similar to wild-type mice

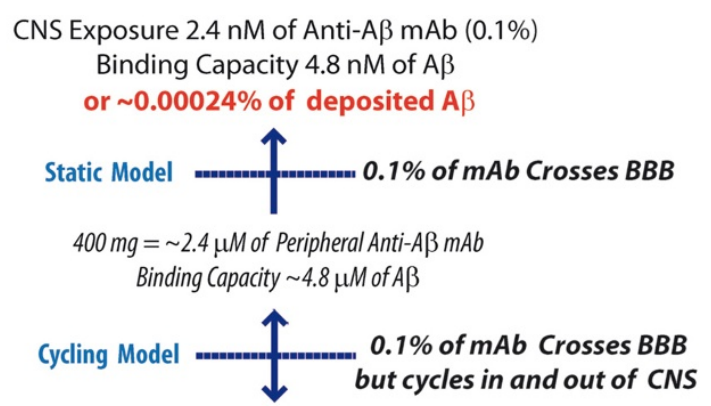

CNS Exposure up to $1200 \mathrm{nM}$ of Anti-A $\beta$ mAb ( 50\%) Binding capacity to $\sim 2400 \mathrm{nM}$ of $\mathrm{A} \beta$ or $12 \%$ of deposited $A \beta$

Figure 1 Comparisons of central nervous system (CNS) monoclonal antibody ( $\mathrm{mAb}$ ) exposure in a static influx model versus a cycling influx and efflux model. Based on estimates that $\sim 20 \mu \mathrm{M}$ of amyloid $\beta$ (A $\beta)(\sim 100 \mathrm{mg})$ are deposited in the Alzheimer's disease brain, the potential target engagement in each model is shown. The parameters used correspond to human studies using a $400 \mathrm{mg}$ dose of anti-A $\mathrm{mAb}$. A method to estimate exposure based on a trapezoidal method for estimating the area under the curve was used with a theoretical cycling time of 1 hour (complete exchange) and antibody half-life of 21 days. In the cycling model, the estimate of how much $A \beta$ could be targeted in the brain is almost certainly an overestimate as the model does not take into account the efficiency of antibody binding within the brain and the extent to which binding of plasma $A \beta$ or other peripheral sources could decrease the amount of free $m A b$ entering the brain. The issue of how much binding of plasma/peripheral $A \beta$ might decrease free $m A b$ exposure in the brain is complex and will be related to the target epitope and antibody affinity. Given an estimate for the daily turnover of $A \beta$ in plasma of $\sim 50 \mathrm{nmol}$, if the mAb bound all plasma $A \beta$ produced in a day and the binding was essentially irreversible (as has been observed for several anti-A $\beta$ mAbs), then that binding would be predicted to reduce the exposure of free antibody in the brain by $\sim 50 \%$. BBB, blood-brain barrier.

following intravenous administration of IgG [16]. Thus, it is clear that additional studies on both antibody influx into and efflux out of the CNS are needed to better understand the mechanism that would regulate antibody exposure in the brain [13]. Other key gaps in our knowledge are whether the $\mathrm{mAb}$ influx into the brain from the periphery results in homogenous $\mathrm{mAb}$ distribution and whether reported dysfunction of the blood-brain barrier in $\mathrm{AD}$ would alter the normal distribution. In this regard, it would be interesting to evaluate whether antibody transport within the brain and efflux from the brain are mediated by the newly described drainage pathway for cerebrospinal fluid [17-19]. This brain-wide clearance pathway, which has been termed the glymphatic system, has been shown to facilitate clearance of solutes from the brain, with cerebrospinal fluid entering along periarteriolar channels where there is solute exchange with interstitial fluid, and then exiting via para-venous pathways [18]. The glymphatic pathway may also be of interest regarding the potential for redistribution of parenchymal amyloid deposits to the vascular deposits as a result of immunotherapy [20]. 


\section{How do target epitope and binding affinity influence potential efficacy in humans?}

Another critical unanswered issue is how the $A \beta$ target epitope and binding affinity influence efficacy in humans $[2,21]$. Based on preclinical studies showing enhanced efficacy of mAbs that bind to $A \beta$, the vast majority of mAbs that have advanced to trials have been selected to bind both monomeric and aggregated forms of $\mathrm{A} \beta$. In many cases, either simply because of increased avidity, recognition of a conformational epitope, or some combination of these properties, these antibodies often appear to have higher affinity for aggregated $A \beta$, and, for the most part, are reported to bind near the amino terminus of $A \beta$ [1]. Solanezumab is the exception; it binds the mid-domain of monomeric, but not aggregated, $\mathrm{A} \beta$ with extremely high affinity $[22,23]$. Although, the human data to date are quite limited, in contrast to what might be predicted based on preclinical studies, solanezumab is the only mAb for which there is evidence of a hint of clinical efficacy in phase 3.

As the notion of targeting pathological $A \beta$ aggregates, either fibrils or oligomers, makes a great deal of conceptual sense in terms of both avoiding targeting presumably nontoxic, non-aggregated forms of $\mathrm{A} \beta$ that could have some physiological role and also potentially increasing exposure of free mAb to the CNS by avoiding binding of plasma $A \beta$, the current negative bapinezumab data and suggestive solanezumab data present the field with somewhat of a dilemma. Moreover, the clinical data raise larger questions of whether we really understand how target epitope and affinity can be optimized to enhance efficacy. For example, do we want an $A \beta$-targeting antibody with extremely high affinity that will bind plaques in the brain and stay bound until degraded? Or do we want an antibody that binds soluble $A \beta$ or soluble $A \beta$ aggregates with modest affinity so that the antibody can carry them to the periphery where they could dissociate and be degraded? Or do we want to target specific modified epitopes of $\mathrm{A} \beta$ that are preferentially found in aggregated forms such as $\mathrm{pE} 3-\mathrm{A} \beta$ or nitrosylated forms of $A \beta$ [24-27]? Unfortunately, given the differences between mouse models of $A \beta$ deposition and the limited data on detailed binding constants that are available for many of the mAbs as well as the lack of comparative binding data [26], these questions may ultimately only be answered by the data that emerge from ongoing human trials, which is a very expensive and inefficient path forward.

In addition to having different biologic activities, binding affinity may skew interpretation of antibody target engagement studies in humans. Antibodies that bind $A \beta$ with high affinity tend to raise plasma $A \beta$ to the greatest extent, probably by preventing the rapid clearance of plasma $A \beta$, which normally has a half-life of approximately 10 minutes $[3,28]$. Although some of the mAb-bound $A \beta$ may have come from $\mathrm{mAb}$ binding in the brain and then the complex being transported to the plasma, it is challenging to distinguish such brain-derived complexes from complexes that form when the antibody binds $A \beta$ in blood. Furthermore, if an antibody has modest affinity for monomeric $A \beta$ and exhibits a relatively rapid off-rate, then it may be difficult to see engagement of monomeric $A \beta$ as assessed by rise in plasma $A \beta$; though the antibody binds $A \beta$, the complex is not stable and thus $A \beta$ will dissociate and be rapidly degraded. In any case, more information on how affinity and other binding properties determine not only clinical efficacy but also $\mathrm{A} \beta$ biomarker changes will help us better understand how these anti-A $\beta$ mAbs are acting in humans and what properties are most predictive of various clinical outcomes.

\section{What is the role of antibody effector function?}

Preclinical studies demonstrate that, depending on the timing of the intervention, antibody effector functions mediated by the Fc region may not be required for efficacy [3,29-31]. In prevention studies in amyloid precursor protein (APP) mice, recombinant antibodies lacking effector functions can be shown to be effective. In contrast, there is some evidence in therapeutic studies targeting $A \beta$ in mice with pre-existing amyloid deposits that antibody effector functions may facilitate or even be required for reduction of deposited $A \beta$ [27]. Anti-A $\beta$ antibodies likely attenuate amyloid deposition through multiple non-exclusive mechanisms that include direct binding and subsequent export from the brain, inhibition of aggregation (even at substoichiometric levels), and enhancing microglial phagocytosis and degradation. Varying conclusions derived from these and other preclinical studies likely reflect the complex actions that antibodies have on CNS amyloid and how those actions are, in part, determined by the pre-existing amyloid load at the time the treatment is initiated [2,21].

As the Fc regions can bind FcR on immune cells (presumably microglial cells in the brain), it is possible that this engagement enhances $A \beta$ phagocytosis and also elicits signaling that could indirectly enhance $A \beta$ clearance. Again, in humans, there is insufficient data to understand the importance of IgG isotype and effector functions, but preliminary reports suggest that utilization of different IgG isotypes or engineered isotypes may have clinical significance. Indeed, crenezumab, which uses an IgG4 backbone with mutations that reduce affinity for FcR [32], appeared in the initial phase I study to avoid amyloid-related imaging abnormalities (ARIAs) even at higher doses than have been tolerated for other anti-A $\beta$ mAbs. Although on the surface this may seem desirable, if $A \beta$ removal is key this could inadvertently impair clearance by limiting glial activation. For example, in early phase human studies of gantenerumab, a fully human anti-A $\beta$ IgG1, there was evidence that the regions of the brain showing radiographic abnormalities 
following antibody administration also showed the highest reduction in signal on subsequent amyloid PIB $\left(C^{11}\right.$ Pittsburgh Compound B) scans [33,34]. Other modifications, such as deglycosylation, that reduce affinity for $\mathrm{Fc} \gamma \mathrm{R}$ and impair ability to bind complement can be shown in mice to reduce potential vascular side effects of anti-A $\beta$ mAbs [35]. However, deglycosylated antibodies that decrease effector function or Fab fragments and single chain antibodies that have no effector functions have not advanced to human studies.

\section{What causes amyloid-related imaging abnormality?}

ARIA is an acronym that refers to both vasogenic edema (ARIA-e) and microhemorrhage (ARIA-H) observed by magnetic resonance imaging (MRI) in patients receiving anti-A $\beta$ immunotherapies [36]. Although cortical microhemorrhage is frequently observed during the natural history of $\mathrm{AD}$ and is thought to be in part related to amyloid angiopathy, vasogenic edema is rarely observed; however, passive immunotherapy with select anti- $\mathrm{A} \beta \mathrm{mAbs}$ (for example, bapinezumab) results in increased ARIAs that appear to be more frequent in APOE4 carriers and increases in frequency with increasing dose of $\mathrm{mAb}$ [37]. In most cases, ARIAs produce no detectable clinical symptoms, but in some cases are associated with acute worsening of cognitive function. Although the prevailing mechanistic theory relates to mobilization of $A \beta$ by the mAb leading to local edema and hemorrhage, no data clearly demonstrate the mechanisms underlying ARIAs. Indeed, it is just as plausible that anti- $\mathrm{A} \beta \mathrm{mAb}$ engages amyloid in vessels leading to focal immune activation and that the inflammation clears the amyloid indirectly. Given the prevalence of ARIAs in the bapinezumab trial and their clear association with escalating dose, an enhanced understanding of ARIAs is needed. Indeed, given the costs associated with MRI and the dose-limiting effect, ARIAs pose a significant obstacle for development of certain mAbs. Certainly, a better understanding of the mechanism underlying ARIAs would streamline $\mathrm{mAb}$ development and perhaps lead to a more optimal immunotherapy.

\section{Why so little news on second generation active vaccines targeting amyloid $\beta$ ?}

Three active anti-A $\beta$ vaccines are in phase II trials for $A D$, but, except for CAD106 (Novartis/Cytos), almost no data have been released regarding their ability to induce anti-A $\beta$ immune responses, avoid side effects observed with the AN-1792 vaccine, and to alter relevant biomarkers [38]. Although a cautious approach is justified given that the vaccines are targeting a self-epitope and thus can induce autoimmune disease, it is puzzling as to why there are so few data, let alone word of mouth insight, regarding how the testing of these vaccine candidates is proceeding. Although most of the second generation anti- $\mathrm{A} \beta$ vaccines are designed to maximize humoral anti- $\mathrm{A} \beta$ responses and minimize harmful T-cell responses, it should be noted that the mechanism responsible for the meningoencephalitic reaction in a subset of patients receiving the AN1792 vaccine remains uncertain $[39,40]$. It has been inferred that the likely cause was harmful T-cell response, but the data supporting this inference are only circumstantial. Moreover, given the rather uneven distribution of the apparent clearance of $A \beta$ in the brain in a handful of subjects who had a postmortem brain autopsy, one has to speculate whether T-cell or other cellular immune mechanisms played a role in clearance [41,42]. Indeed, most T-cell-related disease of the brain is patchy in nature, and it is hard to envisage how there could be extensive focal clearance mediated solely by a peripherally produced $\mathrm{mAb}$.

\section{Anti-tau immunotherapy?}

Multiple reports now demonstrate the therapeutic potential of active and passive immunotherapies for tau, at least in terms of ability to reduce pathological tau burden in mouse models (reviewed in $[21,43,44]$ ). Coupled with reports demonstrating that tau is secreted and that extracellular pathological forms of tau can induce intracellular tau pathology in culture and in mice, there is a burgeoning effort to move both active and passive tau immunotherapies towards the clinic [45-47]. Notably, almost all of the gaps in our knowledge regarding CNS exposure, effector functions, and target epitope discussed above with respect to anti-A $\beta$ immunotherapies apply to tau targeted therapies. Furthermore, though many in the field now accept the potential of tau immunotherapy based on the premise that extracellular tau may be the target, as supported by data from a recent study showing antibodies that block spread of tau seeding in culture also effectively attenuate tau pathology in vivo [48], additional mechanisms should be considered. For example, neurons do express FcR, and therefore could bind and even internalize mAbs [49,50], and, in contrast to the recent report that supports extracellular targeting of tau as a primary mechanism of tau antibodies [48], another recent report provides further evidence that tau antibodies can enter neurons and target intracellular tau [51]. In addition, a recent study has shown that an intracellular protein called TRIM21, which contains a high-affinity Fc-binding domain, can recognize low levels of antibody bound to cargo, ubiquitinate that cargo, and thereby target it for degradation by the proteosome [52]. Thus, it is possible that these mechanisms, or others that are largely under the radar, may contribute to the efficacy of anti-tau immunotherapies. As with anti-A $\beta$ immunotherapies, it is likely that a better understanding of the mechanism will ultimately result in more efficacious and safer immunotherapy. 


\section{What do the failed immunotherapy trials tell us about targeting amyloid $\beta$ in symptomatic Alzheimer's disease patients?}

The amyloid or $\mathrm{A} \beta$ aggregate hypothesis only predicts that preventing $A \beta$ aggregation and accumulation in the brain will prevent the development of AD [53]. It does not predict that clearing deposits in symptomatic patients will have clinical benefit. Furthermore, although slowing ongoing deposition or clearing pre-existing deposits in preclinical stages of $\mathrm{AD}$ might be predicted to have some clinical benefit, there is a reasonable possibility that $\mathrm{A} \beta$ aggregates trigger downstream events that contribute to neurodegeneration that subsequently becomes self-sustaining. If this is the case, then even clearance of $A \beta$ in preclinical $A D$ may have limited efficacy. Studies of postmortem brains from patients previously enrolled in the AN1792 vaccine trial certainly provide some support for the assertion that regional clearance of $A \beta$ is not associated with clinical benefit in patients with $A D$ [41]. In this context, the recent failures of anti-A $\beta$ mAbs to show significant and consistent efficacy are, in fact, likely and not unexpected outcomes.

Another pressing question regarding these trials relates to biologic effects of the mAbs in the brain. Although increased incidence of ARIAs and suggestive evidence that there may be slight reductions in amyloid loads based on serial amyloid scans support target engagement in the brain, the consequences of such engagement are poorly understood [54]. Though practically challenging, efforts to systematically obtain postmortem brains from subjects in these trials would be of major utility for the field. Given the differences between human and mouse brain and the ongoing uncertainties regarding mechanisms of action, rigorous postmortem analyses could provide unique insights into $A \beta$ immunotherapies that might be used to guide future efforts designed to optimize them.

Can we afford suboptimal passive immunotherapies? A final question that relates to public health policy is whether we can afford passive immunotherapy for $\mathrm{AD}$ that has limited clinical benefit? Given the likely costs of a biologic therapy and the ancillary testing (for example, amyloid scans and MRIs) that may be required to prescribe and monitor an approved passive immunotherapy, it is highly likely that the yearly costs of passive immunotherapy for $\mathrm{AD}$ will exceed $\$ 25,000$ to $\$ 30,000$. It is unclear whether any country's health system can afford such therapy if it has a very modest effect on disease course. (Indeed, it is not even clear that we can afford it even if it has a more robust clinical effect.) Furthermore, given set-costs associated with manufacture of antibodies in quantities that would be needed to treat a prevalent disease and the uncertain road map for developing less-expensive generic biosimilars, it is unlikely that costs for such therapy would decline in the foreseeable future. This general issue of cost versus benefit of any novel therapy for most diseases is under increasing scrutiny in many countries and decisions whether to pay or not can have huge socioeconomic implications. Clearly, any convincing evidence that a passive immunotherapy had clinical benefit will be welcome news for the field, but given the changing climate the field may be well-served by more openly discussing the issue of whether society can afford this type of therapy, especially if it has only limited clinical benefit.

\section{Conclusions}

Despite intensive study for over a decade, many aspects of immunotherapy for AD remain enigmatic. Future studies designed to answer questions raised in this review, such as those relating to mechanism of antibody action and factors regulating CNS antibody exposure, could play major roles in guiding development of more optimal therapies. Given the challenges of developing active vaccines that potentially target self-epitopes and thus could induce autoimmune disease, passive immunotherapies, which appear to be relatively safe and have more certainty regarding target engagement, are clearly ideal ways to move forward to evaluate potential efficacy in AD. Given their expense, however, treatment with passive immunotherapies may not represent an ideal long-term public health solution to the $\mathrm{AD}$ epidemic. In contrast, from a public health perspective, vaccines would almost certainly be a cost-effective solution; thus, efforts to develop effective and sufficiently safe vaccines need to be supported.

More generally, there has been a general lack of appreciation for how successful development of $\mathrm{AD}$ vaccines and passive immunotherapies could result in a paradigm shift regarding immunotherapies for many CNS disorders. Largely based on the dogma that only a little antibody gets into the brain, until Schenk and colleagues demonstrated the potential utility of this approach in $\mathrm{AD}$ animal models $[55,56]$, there was essentially no interest in development of antibody-based therapies against CNS targets. Given the ability to develop immunologic reagents with incredible specificity for a given target, if any form of $\mathrm{AD}$ immunotherapy proves efficacious, it is quite possible that in the future we may see antibodies and vaccines used for not only other neurodegenerative disease but even many other neurologic and psychiatric conditions.

\section{Abbreviations}

AD: Alzheimer's disease; ARIA: Amyloid-related imaging abnormality; AB: Amyloid $\beta$; CNS: Central nervous system; FcRn: Neonatal Fc receptor; Ig: Immunoglobulin; mAb: Monoclonal antibody; MRl: Magnetic resonance imaging.

\section{Competing interests}

TEG is co-Editor-in-Chief of Alzheimer's Research \& Therapy and receives an annual honorarium. TEG is an inventor on patents relating to anti-amyloid vaccines and antibodies.

Published: 07 Jan 2014 


\section{References}

1. Prins ND, Scheltens P: Treating Alzheimer's disease with monoclonal antibodies; current status and outlook to the future. Alzheimers Res Ther 2013, 5:56.

2. Golde TE, Das P, Levites Y: Quantitative and mechanistic studies of abeta immunotherapy. CNS Neurol Disord Drug Targets 2009, 8:31-49.

3. Levites Y, Smithson LA, Price RW, Dakin RS, Yuan B, Sierks MR, Kim J, McGowan E, Reed DK, Rosenberry TL, Das P, Golde TE: Insights into the mechanisms of action of anti-Abeta antibodies in Alzheimer's disease mouse models. FASEB J 2006, 20:2576-2578.

4. Atwal JK, Chen Y, Chiu C, Mortensen DL, Meilandt WJ, Liu Y, Heise CE, Hoyte K, Luk W, Lu Y, Peng K, Wu P, Rouge L, Zhang Y, Lazarus RA, Scearce-Levie K, Wang W, Wu Y, Tessier-Lavigne M, Watts RJ: A therapeutic antibody targeting BACE1 inhibits amyloid-beta production in vivo. Sci Trans/ Med 2011, 3:84ra43.

5. Yu YJ, Zhang Y, Kenrick M, Hoyte K, Luk W, Lu Y, Atwal J, Elliott JM, Prabhu S, Watts RJ, Dennis MS: Boosting brain uptake of a therapeutic antibody by reducing its affinity for a transcytosis target. Sci Trans/ Med 2011, 3:84ra44.

6. DeMattos RB, Bales KR, Cummins DJ, Paul SM, Holtzman DM: Brain to plasma amyloid-beta efflux: a measure of brain amyloid burden in a mouse model of Alzheimer's disease. Science 2002, 295:2264-2267.

7. Bickel U, Yoshikawa T, Pardridge WM: Delivery of peptides and proteins through the blood-brain barrier. Adv Drug Deliv Rev 2001, 46:247-279.

8. Lee HJ, Engelhardt B, Lesley J, Bickel U, Pardridge WM: Targeting rat anti-mouse transferrin receptor monoclonal antibodies through blood-brain barrier in mouse. J Pharmacol Exp Ther 2000, 292:1048-1052.

9. Thakker DR, Weatherspoon MR, Harrison J, Keene TE, Lane DS, Kaemmerer WF, Stewart GR, Shafer LL: Intracerebroventricular amyloid-beta antibodies reduce cerebral amyloid angiopathy and associated micro-hemorrhages in aged Tg2576 mice. Proc Natl Acad Sci U S A 2009, 106:4501-4506.

10. Paganetti P, Reichwald J, Bleckmann D, Abramowski D, Ammaturo D, Barske C, Danner S, Molinari M, Müller M, Papin S, Rabe S, Schmid P, Staufenbiel M: Transgenic expression of beta1 antibody in brain neurons impairs age-dependent amyloid deposition in APP23 mice. Neurobiol Aging 2013, 34:2866-2878

11. Irani SR, Vincent A: NMDA receptor antibody encephalitis. Curr Neurol Neurosci Rep 2011, 11:298-304.

12. Panzer J, Dalmau J: Movement disorders in paraneoplastic and autoimmune disease. Curr Opin Neurol 2011, 24:346-353.

13. Strazielle N, Ghersi-Egea JF: Physiology of blood-brain interfaces in relation to brain disposition of small compounds and macromolecules. Mol Pharm 2013, 10:1473-1491.

14. Zhang Y, Pardridge WM: Mediated efflux of IgG molecules from brain to blood across the blood-brain barrier. J Neuroimmunol 2001, 114:168-172.

15. Deane R, Sagare A, Hamm K, Parisi M, LaRue B, Guo H, Wu Z, Holtzman DM, Zlokovic BV: IgG-assisted age-dependent clearance of Alzheimer's amyloid beta peptide by the blood-brain barrier neonatal Fc receptor. J Neurosci 2005, 25:11495-11503.

16. Abuqayyas L, Balthasar JP: Investigation of the role of FcgammaR and FcRn in mAb distribution to the brain. Mol Pharm 2013, 10:1505-1513.

17. Iliff JJ, Lee H, Yu M, Feng T, Logan J, Nedergaard M, Benveniste H: Brain-wide pathway for waste clearance captured by contrast-enhanced MRI. J Clin Invest 2013, 123:1299-1309.

18. Iliff JJ, Wang M, Liao Y, Plogg BA, Peng W, Gundersen GA, Benveniste H, Vates GE, Deane R, Goldman SA, Nagelhus EA, Nedergaard M: A paravascular pathway facilitates CSF flow through the brain parenchyma and the clearance of interstitial solutes, including amyloid beta. Sci Trans/ Med 2012, 4:147ra111.

19. Yang L, Kress BT, Weber HJ, Thiyagarajan M, Wang B, Deane R, Benveniste $H$, $\|$ iff JJ, Nedergaard M: Evaluating glymphatic pathway function utilizing clinically relevant intrathecal infusion of CSF tracer. J Trans/ Med 2013, 11:107.

20. Weller RO, Preston SD, Subash M, Carare RO: Cerebral amyloid angiopathy in the aetiology and immunotherapy of Alzheimer disease. Alzheimers Res Ther 2009, 1:6.

21. Yu YJ, Watts RJ: Developing therapeutic antibodies for neurodegenerative disease. Neurotherapeutics 2013, 10:459-472.

22. Seubert P, Barbour R, Khan K, Motter R, Tang P, Kholodenko D, Kling K, Schenk D, Johnson-Wood K, Schroeter S, Gill D, Jacobsen JS, Pangalos M, Basi G, Games D: Antibody capture of soluble Abeta does not reduce cortical Abeta amyloidosis in the PDAPP mouse. Neurodegener Dis 2008, $5: 65-71$
23. Dodart JC, Bales KR, Gannon KS, Greene SJ, DeMattos RB, Mathis C, DeLong CA Wu S, Wu X, Holtzman DM, Paul SM: Immunization reverses memory deficits without reducing brain Abeta burden in Alzheimer's disease model. Nat Neurosci 2002, 5:452-457.

24. Jawhar S, Wirths O, Bayer TA: Pyroglutamate amyloid-beta (Abeta): a hatchet man in Alzheimer disease. J Biol Chem 2011, 286:38825-38832.

25. Kummer MP, Hermes M, Delekarte A, Hammerschmidt T, Kumar S, Terwel D, Walter J, Pape HC, König S, Roeber S, Jessen F, Klockgether T, Korte M, Heneka MT: Nitration of tyrosine 10 critically enhances amyloid beta aggregation and plaque formation. Neuron 2011, 71:833-844.

26. Frost JL, Le KX, Cynis H, Ekpo E, Kleinschmidt M, Palmour RM, Envin FR, Snigdha S, Cotman CW, Saido TC, Vassar RJ, St George-Hyslop P, Ikezu T, Schilling S, Demuth HU, Lemere CA: Pyroglutamate-3 amyloid-beta deposition in the brains of humans, non-human primates, canines, and Alzheimer disease-like transgenic mouse models. Am J Pathol 2013, 183:369-381.

27. Demattos RB, Lu J, Tang Y, Racke MM, Delong CA, Tzaferis JA, Hole JT, Forster BM, McDonnell PC, Liu F, Kinley RD, Jordan WH, Hutton ML: A plaque-specific antibody clears existing beta-amyloid plaques in Alzheimer's disease mice. Neuron 2012, 76:908-920.

28. DeMattos RB, Bales KR, Cummins DJ, Dodart JC, Paul SM, Holtzman DM: Peripheral anti-A beta antibody alters CNS and plasma A beta clearance and decreases brain A beta burden in a mouse model of Alzheimer's disease. Proc Natl Acad Sci U S A 2001, 98:8850-8855.

29. Levites Y, Jansen K, Smithson LA, Dakin R, Holloway VM, Das P, Golde TE: Intracranial adeno-associated virus-mediated delivery of anti-pan amyloid beta, amyloid beta 40 , and amyloid beta 42 single-chain variable fragments attenuates plaque pathology in amyloid precursor protein mice. I Neurosci 2006, 26:11923-11928.

30. Das P, Howard V, Loosbrock N, Dickson D, Murphy MP, Golde TE: Amyloid-beta immunization effectively reduces amyloid deposition in FcRgamma-/knock-out mice. J Neurosci 2003, 23:8532-8538.

31. Bacskai BJ, Kajdasz ST, McLellan ME, Games D, Seubert P, Schenk D, Hyman BT: Non-Fc-mediated mechanisms are involved in clearance of amyloid-beta in vivo by immunotherapy. J Neurosci 2002, 22:7873-7878,

32. Adolfsson O, Pihlgren $\mathrm{M}$, Toni N, Varisco Y, Buccarello AL, Antoniello $\mathrm{K}$, Lohmann S, Piorkowska K, Gafner V, Atwal JK, Maloney J, Chen M, Gogineni A, Weimer RM, Mortensen DL, Friesenhahn M, Ho C, Paul R, Pfeifer A, Muhs A, Watts RJ: An effector-reduced anti-beta-amyloid (Abeta) antibody with unique abeta binding properties promotes neuroprotection and glial engulfment of Abeta. J Neurosci 2012, 32:9677-9689.

33. Ostrowitzki S, Deptula D, Thurfjell L, Barkhof F, Bohrmann B, Brooks DJ, Klunk WE, Ashford E, Yoo K, Xu ZX, Loetscher H, Santarelli L: Mechanism of amyloid removal in patients with Alzheimer disease treated with gantenerumab. Arch Neurol 2012, 69:198-207.

34. Bohrmann B, Baumann K, Benz J, Gerber F, Huber W, Knoflach F, Messer J, Oroszlan K, Rauchenberger R, Richter WF, Rothe C, Urban M, Bardroff M, Winter M, Nordstedt C, Loetscher H: Gantenerumab: a novel human anti-Abeta antibody demonstrates sustained cerebral amyloid-beta binding and elicits cell-mediated removal of human amyloid-beta. J Alzheimers Dis 2012, 28:49-69.

35. Wilcock DM, Alamed J, Gottschall PE, Grimm J, Rosenthal A, Pons J, Ronan V, Symmonds K, Gordon MN, Morgan D: Deglycosylated anti-amyloid-beta antibodies eliminate cognitive deficits and reduce parenchymal amyloid with minimal vascular consequences in aged amyloid precursor protein transgenic mice. J Neurosci 2006, 26:5340-5346,

36. Sperling RA, Jack CR Jr, Black SE, Frosch MP, Greenberg SM, Hyman BT, Scheltens P, Carrillo MC, Thies W, Bednar MM, Black RS, Brashear HR, Grundman M, Siemers ER, Feldman HH, Schindler R: Amyloid-related imaging abnormalities in amyloid-modifying therapeutic trials: recommendations from the Alzheimer's Association Research Roundtable Workgroup. Alzheimers Dement 2011, 7:367-385.

37. Sperling R, Salloway S, Brooks DJ, Tampieri D, Barakos J, Fox NC, Raskind M Sabbagh M, Honig LS, Porsteinsson AP, Lieberburg I, Arrighi HM, Morris KA, Lu Y, Liu E, Gregg KM, Brashear HR, Kinney GG, Black R, Grundman M: Amyloid-related imaging abnormalities in patients with Alzheimer's disease treated with bapineuzumab: a retrospective analysis. Lancet Neurol 2012, 11:241-249.

38. Winblad B, Andreasen N, Minthon L, Floesser A, Imbert G, Dumortier T, Maguire RP, Blennow K, Lundmark J, Staufenbiel M, Orgogozo JM, Graf A: Safety, tolerability, and antibody response of active Abeta immunotherapy with CAD106 in patients with Alzheimer's disease: 
randomised, double-blind, placebo-controlled, first-in-human study. Lancet Neurol 2012, 11:597-604.

39. Gilman S, Koller M, Black RS, Jenkins L, Griffith SG, Fox NC, Eisner L, Kirby L, Rovira MB, Forette F, Orgogozo JM, AN1792(QS-21)-201 Study Team: Clinical effects of Abeta immunization (AN1792) in patients with $A D$ in an interrupted trial. Neurology 2005, 64:1553-1562.

40. Orgogozo JM, Gilman S, Dartigues JF, Laurent B, Puel M, Kirby LC, Jouanny P, Dubois B, Eisner L, Flitman S, Michel BF, Boada M, Frank A, Hock C: Subacute meningoencephalitis in a subset of patients with $A D$ after Abeta42 immunization. Neurology 2003, 61:46-54.

41. Holmes C, Boche D, Wilkinson D, Yadegarfar G, Hopkins V, Bayer A, Jones RW, Bullock R, Love S, Neal JW, Zotova E, Nicoll JA: Long-term effects of Abeta42 immunisation in Alzheimer's disease: follow-up of a randomised, placebocontrolled phase I trial. Lancet 2008, 372:216-223.

42. Boche D, Donald J, Love S, Harris S, Neal JW, Holmes C, Nicoll JA: Reduction of aggregated Tau in neuronal processes but not in the cell bodies after Abeta42 immunisation in Alzheimer's disease. Acta Neuropathol 2010, 120:13-20.

43. Sigurdsson EM: Immunotherapy targeting pathological tau protein in Alzheimer's disease and related tauopathies. J Alzheimers Dis 2008, 15:157-168.

44. Gu J, Sigurdsson EM: Immunotherapy for tauopathies. J Mol Neurosci 2011, 45:690-695.

45. Yamada K, Cirrito JR, Stewart FR, Jiang H, Finn MB, Holmes BB, Binder LI, Mandelkow EM, Diamond MI, Lee VM, Holtzman DM: In vivo microdialysis reveals age-dependent decrease of brain interstitial fluid tau levels in P301S human tau transgenic mice. J Neurosci 2011, 31:13110-13117.

46. Liu L, Drouet V, Wu JW, Witter MP, Small SA, Clelland C, Duff K: Trans-synaptic spread of tau pathology in vivo. PLoS One 2012, 7:e31302.

47. de Calignon A, Polydoro M, Suárez-Calvet M, William C, Adamowicz DH, Kopeikina KJ, Pitstick R, Sahara N, Ashe KH, Carlson GA, Spires-Jones TL, Hyman BT: Propagation of tau pathology in a model of early Alzheimer's disease. Neuron 2012, 73:685-697.

48. Yanamandra K, Kfoury N, Jiang H, Mahan TE, Ma S, Maloney SE, Wozniak DF, Diamond MI, Holtzman DM: Anti-Tau antibodies that block Tau aggregate seeding in vitro markedly decrease pathology and improve cognition in vivo. Neuron 2013, 80:402-414.

49. Fernandez-Vizarra P, Lopez-Franco O, Mallavia B, Hiquera-Matas A, Lopez-Parra V Ortiz-Munoz G, Ambrosio E, Egido J, Almeida OF, Gomez-Guerrero C: Immunoglobulin G Fc receptor deficiency prevents Alzheimer-like pathology and cognitive impairment in mice. Brain 2012, 135:2826-2837.

50. Deng J, Hou H, Giunta B, Mori T, Wang YJ, Fernandez F, Weggen S, Araki W, Obregon D, Tan J: Autoreactive-Abeta antibodies promote APP beta-secretase processing. J Neurochem 2012, 120:732-740.

51. Gu J, Congdon EE, Sigurdsson EM: Two novel tau antibodies targeting the 396/ 404 region are primarily taken up by neurons and reduce tau pathology. J Biol Chem 2013 [epub ahead of print].

52. McEwan WA, Mallery DL, Rhodes DA, Trowsdale J, James LC: Intracellular antibody-mediated immunity and the role of TRIM21. Bioessays 2011, 33:803-809.

53. Golde TE, Schneider LS, Koo EH: Anti-abeta therapeutics in Alzheimer's disease: the need for a paradigm shift. Neuron 2011, 69:203-213.

54. Rinne JO, Brooks DJ, Rossor MN, Fox NC, Bullock R, Klunk WE, Mathis CA Blennow K, Barakos J, Okello AA, Rodriguez Martinez de Liano S, Liu E, Koller M, Gregg KM, Schenk D, Black R, Grundman M: 11C-PiB PET assessment of change in fibrillar amyloid-beta load in patients with Alzheimer's disease treated with bapineuzumab: a phase 2 , double-blind, placebo-controlled, ascending-dose study. Lancet Neurol 2010, 9:363-372.

55. Schenk D, Barbour R, Dunn W, Gordon G, Grajeda H, Guido T, Hu K, Huang J, Johnson-Wood K, Khan K, Kholodenko D, Lee M, Liao Z, Lieberburg I, Motter R, Mutter L, Soriano F, Shopp G, Vasquez N, Vandevert C, Walker S, Wogulis M, Yednock T, Games D, Seubert P: Immunization with amyloid-beta attenuates Alzheimer-disease-like pathology in the PDAPP mouse. Nature 1999, 400:173-177.
56. Bard F, Cannon C, Barbour R, Burke RL, Games D, Grajeda H, Guido T, Hu K, Huang J, Johnson-Wood K, Khan K, Kholodenko D, Lee M, Lieberburg I, Motter R, Nguyen M, Soriano F, Vasquez N, Weiss K, Welch B, Seubert P, Schenk D, Yednock $\mathrm{T}$ : Peripherally administered antibodies against amyloid beta-peptide enter the central nervous system and reduce pathology in a mouse model of Alzheimer disease. Nat Med 2000, 6:916-919.

\subsection{6/alzrt233}

Cite this article as: Golde: Open questions for Alzheimer's disease immunotherapy. Alzheimer's Research \& Therapy 2014, 6:3 